Chirurgia (2018) 113: 789-798

No. 6, November - December

Copyright $@$ Celsius

http://dx.doi.org/10.21614/chirurgia.113.6.789

\title{
The Value of Staging Laparoscopy for Optimal Multidisciplinary Treatment in Patients with Gastric Cancer
}

\author{
Vasile V. Bintintan'1, Andreea Cordoș', Romeo Chira', Simona Cocu², Paul Rus', Adriana Bintintan², Georgiana Nagy', \\ Larisa Ciule' ${ }^{2}$ Emanuel Cata', Andrei Pop ${ }^{1}$, Vlad Fagarasan', Andrei Ungureanu ${ }^{3}$, Valeriu Surlin ${ }^{4}$, Dan Timofte, \\ Kim Young $\mathrm{Woo}^{6}$, Constantin Ciuce', George Dindelegan'
}

'University of Medicine and Pharmacy Cluj Napoca, Romania

${ }^{2}$ County Emergency Hospital Cluj, Romania

${ }^{3}$ Amethyst Center Cluj, Romania

${ }^{4}$ University of Medicine and Pharmacy Craiova, Romania

EUniversity of Medicine and Pharmacy lasi, Romania

${ }^{6}$ National Cancer Center Seoul, South Korea

Corresponding author:

Andreea Cordos M.D.

University of Medicine and Pharmacy

Cluj Napoca, Romania

E-mail: cordos.andreea1@gmail.com

Abbreviations:

CE-CT: contrast-enhanced computer tomography;

CT: computer tomography;

EUS: Endoscopic ultrasonography;

LUS: Laparsocopic ultrasonography;

T stage: tumoral stage;

N stage: lymph node stage;

$M$ stage: metastatic stage

$\mathrm{N}+$ : lymph node metastases;

Gl: gastrointestinal.

Received: 10.10 .2018

Accepted: 15.12 .2018

\section{Rezumat}

Rolul laparoscopiei de stadializare în optimizarea tratamentului multidisciplinar al pacientilor cu cancer gastric

Introducere: În ciuda progreselor făcute de metodele convenționale de stadializare în cancerul gastric, acuratețea rezultatelor lor este încă suboptimală. Laparoscopia are potențialul de a vizualiza şi caracteriza morfologic tumora, cavitatea peritoneală şi limfoganglionii loco-regionali şi astfel de a selecta mai bine pacienții pentru strategia optimă de tratament.

Material şi Metodă: Pacienții cu cancer gastric stadializați inițial prin computer tomografie şi ecografie endoscopică au fost evaluați folosind laparoscopia şi ecografia intraoperatorie laparoscopică ca şi procedură distinctă de stadializare preoperatorie. Datele perioperatorii au fost folosite pentru a decide în echipa multidisciplinară strategia terapeutică optimă pentru fiecare pacient, au fost înregistrate într-o baza de date prospectivă şi analizate retrospectiv în cadrul acestui studiu.

Rezultate: Între cei 20 pacienți analizați stadializați M0 pe examinarea computer tomografică, $15 \%$ au prezentat carcinomatoză peritoneală extinsă. În alte $15 \%$ din cazuri laparoscopia a avut ca efect creşterea nivelului de stadializare şi inițierea chimioterapiei neoadjuvantă. În trei cazuri biopsia percutanată cu ac Tru-cut ghidată laparoscopic a permis stabilirea diagnosticului 
definitiv şi inițierea tratementului adecvat. În total, laparoscopia a adus informații relevante în $65 \%$ din cazuri si a schimbat planul de tratament la $30 \%$ dintre pacienț.

Concluzii: În era chimioterapiei neoadjuvante pentru cancerul gastric, laparoscopia este un instrument util de stadializare care are potențialul de a depăşi limitele metodelor tradiționale şi de a oferi informații relevante ce pot schimba planul de tratament la un procent de până la $30 \%$ dintre pacienți.

Cuvinte cheie: laparoscopie, stadializare, cancer gastric

\begin{abstract}
Introduction: Despite improvements in the conventional preoperative tools used for staging of gastric cancer, their accuracy still needs to be improved. Laparoscopy has the potential to visualize and characterize the tumor, the peritoneal cavity and the lymph nodes and thus to better select patients for the optimal treatment strategy.

Material and Method: Patients with gastric cancer staged initially with contrast enhanced computer tomography and endoscopic ultrasound were also evaluated by laparoscopy and laparoscopic ultrasound in a distinct preoperative staging procedure. The perioperative data was recorded in a prospective database and was used to decide within the multidisciplinary team the optimal treatment protocol for each patient. The database was retrospectively reviewed for this study.

Results: Among the $20 \mathrm{CT}^{-}$scan M0 patients analyzed, peritoneal carcinomatosis was detected in $15 \%$ of the cases. In other $15 \%$ of patients laparoscopy upstaged the tumor and directed the patient towards neoadjuvant chemotherapy. Laparoscopic guided percutaneous core biopsies settled the definitive diagnosis in 3 further cases. In total, laparoscopic staging brought important information in $65 \%$ of cases and changed the treatment plan in $30 \%$ of patients.

Conclusions: In the era of neoadjuvant chemotherapy, laparoscopy has the potential to overcome some of the limitations of the conventional staging methods and offers additional informations which finally change the treatment plan in as much as a third of patients with gastric cancer.
\end{abstract}

Key words: laparoscopy, staging, gastric cancer

\section{Introduction}

Due to its aggressive behavior and lack of screening programs except for certain Asiatic regions, most patients with gastric cancer already have an advanced loco-regional and even systemic disease by the time of diagnosis. The risk of peritoneal carcinomatosis in early gastric cancer is up to $4 \%$ while in locally advanced tumors (T3-4, N+) it raises to $25 \%$ (1). Discovering signs of systemic disease, such as small peritoneal deposits of carcinomatosis less than $5 \mathrm{~mm}$, is difficult even with the recent advances in contrast-enhanced computed tomography scans (CE-CT).

The MAGIC trial has produced profound changes in the management of gastric cancer, introducing the concept of perioperative chemotherapy (2). This new multidisciplinary treatment protocol comprising three cycles of chemotherapy followed by surgery and further three cycles of chemotherapy offered a $12.5 \%$ increase in the 5-years survival rate of patients compared with surgery alone (2), significantly higher than the $5.8 \%$ increase offered by the adjuvant chemotherapy protocol (3). In light of these results, the policy of perioperative chemotherapy for advanced gastric cancer was rapidly adopted by the majority of Western gastric cancer centers and is nowadays the preferred approach for the treatment of T3-4 N0-3 gastric tumors even if they are perfectly 
resectable at the time of diagnosis. In light of these data, accurate staging for the $\mathrm{T}$ and $\mathrm{N}$ stages became even more crucial than before.

Endoscopic ultrasound is used to evaluate the $\mathrm{T}$ stage but its overall accuracy is a mere $75 \%$ while the capacity to discriminate between T2 and T3 invasion of the gastric wall is quite low since local inflammation might be mistaken as tumor invasion $(4,5)$. As far as nodal staging is concerned, peritumoral lymph nodes can be characterized by EUS and even biopsied with a fine needle (FNAB) with an overall accuracy of $92-93 \% \quad(6,7)$. CE-CT visualizes the tumor, assesses its resecability and characterizes local and regional lymph nodes. Overall, it has a $71 \%$ accuracy rate for detecting T-stage, $66 \%$ for $\mathrm{N}$-stage, and $81 \%$ for $\mathrm{M}$-stage but has low accuracy to discriminate between $\mathrm{T} 1$ and $\mathrm{T} 2$ tumors (8). The rate of agreement between CE-CT and EUS is also far from optimal; there are patients which fall in different treatment categories depending on the staging tool used (9).

The multidisciplinary perioperative treatment of gastric cancer has become the accepted paradigm in Western Europe where most of the patients present with stages higher than T2N0 and represents also our standard policy. In this respect, it is now crucial to differentiate a T2 from a T3 tumor and to identify presence of metastatic lymph nodes, not only using the imagistic criteria but also by taking biopsies from them in uncertain cases. Furthermore, in patients with advanced tumors it is vital to know if there is localized peritumoral carcinomatosis before the initiation of neoadjuvant chemotherapy in order to excise that area at the time of definite radical surgery. If the tumor responded adequately to chemotherapy, that area might not be visible anymore.

In light of all these data, there is a real need for a staging tool that can offer additional information, overcome the limitations of CE-CT and EUS, solve their eventual disagreements and settle the patient on the correct treatment plan.

Exploratory laparoscopy allows direct inspection of peritoneal surface and biopsy of suspected nodules, visualizes the tumor and, with the help of laparoscopic intraoperative ultrasound (LUS), may differentiate better between T2 and T3 stages. Regarding the N stage, laparoscopy allows characterization of loco-regional lymph nodes either by direct visualization or by LUS scanning and has the potential to remove an entire lymph node for an extensive pathological examination. It also assesses resectability of the tumor in cases uncertain on the CE-CT examination, allows sampling of peritoneal fluid for cytological examination and can be coupled with laparoscopic ultrasound scanning of the liver for occult metastases.

All these advantages qualify laparoscopy as a powerful staging tool but, despite its proven value, it is still scarcely used in the clinical practice. Even when used, it is frequently planned as an introductory step for the radical gastric resection which adds pressure on the operative team to finish it in due time, a practice that often results in incomplete and rushed staging, with limited overall value.

We believe in the value of laparoscopy and started to use it extensively in the multimodal treatment of our patients with gastric cancer. To evaluate objectively which is the benefit laparoscopy adds to the decision making in these patients, we have recorded the perioperative data of our patients in a prospective data base and analyzed the results retrospectively. The main aim of this study was to evaluate in which percentage of cases the information provided by laparoscopic staging brought additional data to the multidisciplinary team and in which percentage it actually changed the treatment strategy and sequence of therapeutic procedures in our patients.

\section{Material and Method}

\section{Inclusion Criteria}

Between October 2014 and November 2018 patients with gastric cancer managed by our multidisciplinary team have been considered for staging laparoscopy as part of our standardized treatment protocol. All patients were initially staged with contrast-enhanced CT scan of thorax, abdomen and pelvis, and in 
all except one case with endoscopic ultrasound (EUS) as well, the specific role of EUS being to differentiate between $\mathrm{T} 2$ and T3 tumors. Patients unfit for laparoscopy or those in which laparoscopy had no potential to change the therapeutic plan, namely those with very early tumors (Tis or $\mathrm{T} 1$ and small diameter $\leq 2 \mathrm{~cm})$ or, oppositely, with gross systemic metastatic disease detected on CT scan, were excluded from this study. The aim of staging laparoscopy was either to exclude peritoneal carcinomatosis or to provide the definitive, accurate selection of patients that need to be included in the perioperative chemotherapy treatment protocol. In this respect, when there was controversy of $\mathrm{T}$ or $\mathrm{N}$ stage on $\mathrm{CT}$ scan and EUS, laparoscopy with laparoscopic ultrasonography (LUS) aimed to provide the final answer. All patients were broadly informed about the treatment strategy used, about the role of laparoscopic staging in the final decision-making and gave informed consent to the procedure according to the standard policy of our institution.

\section{Surgical Technique}

Staging laparoscopy was scheduled as an independent staging procedure; it was not intended to be followed by the radical resection in the same anesthetic event even in cases in which the latter would be considered to be adequate. The operation was performed in general anesthesia with the patient placed in the French position. A $10 \mathrm{~mm}$ trocar, for the 30-degree laparoscope, was inserted into the umbilicus and two additional working ports (5 $\mathrm{mm}$ on right side and $10 \mathrm{~mm}$ on left side of the patient) were added into the mid-claviculary lines bilaterally, on the umbilical line. Prior to any manipulation, a standardized visual inspection of the entire peritoneal cavity was performed, carefully looking for peritoneal carcinomatosis, ascites, liver metastases and suspected lymph nodes, starting from the right quadrant. The surfaces of the liver, diaphragm, parietal peritoneum, omentum, serosal surfaces of small bowel, root of the mesentery, posterior surface of the transverse mesocolon, parieto-colic spaces and pelvic organs were carefully inspected (Fig. 1). If present, ascitic fluid was aspirated and sent for cytology. In T3 or T4 cases, peritoneal washings were performed with instillation of $200 \mathrm{ml}$ saline and were sampled for cytological assessment. Biopsies were taken if there were any suspect peritoneal nodules. The anterior wall of the stomach was exposed by lifting the left lobe of the liver; the posterior wall was inspected by entering the bursa omentalis through a $3-5 \mathrm{~cm}$ incision into the gastro-colic ligament. The tumor was inspected for serosal invasion and infiltration into surrounding structures and LUS was used to identify the depth of tumor penetration into the gastric wall (Fig. 2). When the tumor was localized on the posterior wall, a careful evaluation was performed to see if the retroperitoneum was invaded. The exact position of the tumor's margins was also documented and compared with the endoscopic and CT findings to determine the future lines of resection. Lymph nodes along the greater and lesser curvature, in the hepatic pedicle and the gastrohepatic ligament were inspected, analyzed by LUS and biopsied if suspect (Fig. 3).

Data provided by laparoscopic staging was recorded in a prospective database, assessed after the operation and discussed within the oncological board. Based on these informations,

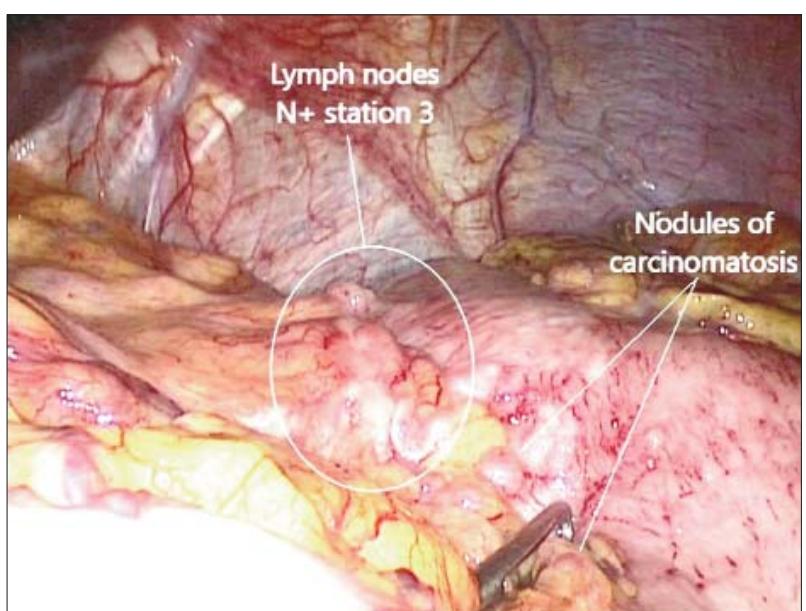

Figure 1. Carcinomatosis on the lesser omentum and along the lesser curvature of the stomach with additional metastatic lymph nodes in stations 3 and 7 . 

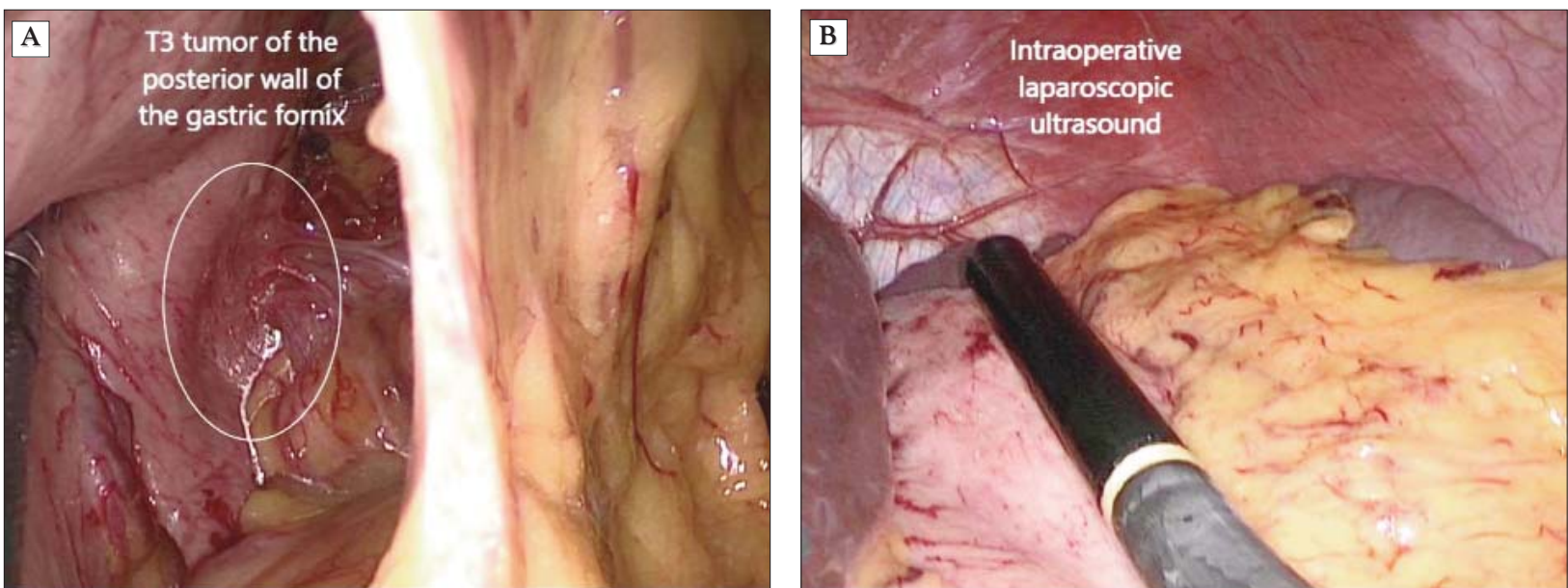

Figure 2. (A) Inspection of a T3 gastric tumor on the posterior wall of the fornix. (B) Laparoscopic ultrasound of the gastric wall for T staging.

the patient was referred to one of the three possible treatment pathways: i) gastric resection, ii) perioperative chemotherapy followed by gastric resection or iii) palliation. In patients staged T1-2N0M0 surgery (i.e. radical gastric resection with D2 lymphadenectomy defined after the Japanese classification) was performed within the next 2-3 days after laparoscopic staging. Patients with higher stages were referred to the perioperative chemotherapy protocol consisting of $3-4$ cycles of platinum based chemotherapy followed by surgery after three weeks and by further 3-2 cycles of post-operative chemotherapy. Tumor

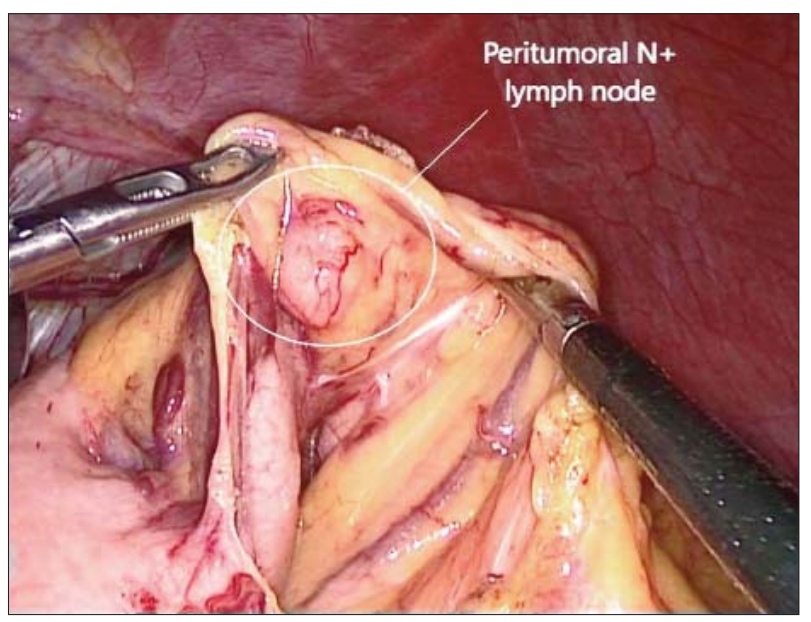

Figure 3. Macroscopically suspect peritumoral lymph node in station 4sa in a patient with signet cell carcinoma of the gastric fornix response to chemotherapy was assessed before radical surgery by a second abdominal CT scan. Patients with positive peritoneal cytology alone or limited localized carcinomatosis detected on staging laparoscopy were submitted to 4 cycles of chemotherapy followed by imagistic reevaluation. If the disease did not progress on the re-evaluation $\mathrm{CT}$ scan, extensive resection was performed that included peritoneotectomy of the area involved by carcinomatosis at the time of staging laparoscopy followed by further cycles of adjuvant chemotherapy.

\section{Collection of Data}

Demographic data, clinical information including tumor site, histological type, TNM stage set by CT scan \pm EUS, TNM staged based on laparoscopic staging and other intraoperative findings were recorded in a prospective database at the end of laparoscopic staging and at the time of patient's discharge from the hospital. Descriptive analysis of the TNM stage assessed by CT scan, EUS, and staging laparoscopy was presented.

\section{Results}

A total number of twenty patients were included in this study (Table 1). Indication for laparoscopy was: i) suspicion of peritoneal carcinomatosis on CT scan (cases 7 and 8), ii) advanced loco- 
Table 1. Clinical and pathologic characteristics of the patients included in study.

\begin{tabular}{|c|c|c|c|c|c|c|c|}
\hline Patients & $\begin{array}{l}\text { Gastric Tumor } \\
\text { Site }\end{array}$ & $\begin{array}{l}\text { cTNM by } \\
\text { CT scan }\end{array}$ & $\begin{array}{l}\text { cTNM } \\
\text { by EUS }\end{array}$ & $\begin{array}{l}\text { cTNM by } \\
\text { Stag-Lap }\end{array}$ & $\begin{array}{l}\text { Neoadjuvant } \\
\text { CHT }\end{array}$ & Definitive treatment & (y)pTNM \\
\hline Case1 & corpus & T2/3N1M0 & T3 & $\mathrm{T} 4 \mathrm{bN0}{ }^{\circ} \mathrm{M} 0 *$ & 3EOX & Gastrectomy+D2 lymphadenectomy & T3N0M0 \\
\hline Case 2 & cardia & T3N2MO & NP & $\mathrm{T} 3 \mathrm{~N} 2^{\circ} \mathrm{M} 0^{*}$ & $3 \mathrm{EOX}$ & Gastrectomy +D2 lymphadenectomy & T3NOMO \\
\hline Case 3 & corpus & T3NOMO & T3N1 & $\mathrm{T} 3 \mathrm{~N} 1 *^{\circ} \mathrm{MO}$ & - & $\mathrm{IPP}^{\mu}$ & Chronic gastritis \\
\hline Case 4 & fundus & T3N1M0 & T1N0 & $\mathrm{T} 3 \mathrm{~N} 1^{\circ} \mathrm{MO}$ & 3ECX & Gastrectomy +D2 lymphadenectomy & $\begin{array}{l}\text { TONOMO - } \\
\text { complete } \\
\text { remission }\end{array}$ \\
\hline Case 5 & small curvature & T2N1M0 & T1N2 & $\mathrm{T} 2 \mathrm{~N} 2^{\circ} \mathrm{MO}$ & 3ECX & Gastrectomy+D2 lymphadenectomy & T3NOMOL1 \\
\hline Case 6 & cardia & $\mathrm{T} 4 \mathrm{a} / \mathrm{b} * \star \mathrm{N} 2 \mathrm{M} 0$ & $\mathrm{~T} 4 \mathrm{a}^{* *}$ & T4aN2MO & 3EOX & Gastrostomy & $\begin{array}{c}\text { Extended } \\
\text { carcinomatosis }\end{array}$ \\
\hline Case 7 & small curvature & T3N1M? & NP & $\begin{array}{c}\text { M1 } \\
\text { (extended } \\
\text { carcinomatosis) }\end{array}$ & - & Palliative chemotherapy & - \\
\hline Case 8 & corpus & T4N2MO & NP & $\begin{array}{l}\mathrm{M} 1^{\circ} \\
\text { (extended } \\
\text { carcinomatosis) }\end{array}$ & - & Gastrostomy & - \\
\hline Case 9 & corpus & T2NOMO & NP & T2NOMO & No & Gastrectomy+D2 lymphadenectomy & T2N1 \\
\hline Case 10 & corpus & T3N1M0 & NP & T3N1M0 & 3EOX & Gastrectomy+D2 lymphadenectomy & T3NO \\
\hline Case 11 & corpus & T2/3NOMO & T3NOMO & T4N1M? & 3 FLOT & $\begin{array}{l}\text { Gastrectomy+D2 lymphadenectomy } \\
\text { + excision of a } 1 \mathrm{~cm} \text { tumor on the } \\
\text { hepatic capsule }\end{array}$ & T3N2M1 \\
\hline Case 12 & corpus & T3N2MO & NP & T4aN2MO & 3FLOT & $\begin{array}{l}\text { Subtotal gastrectomy+D2 } \\
\text { lymphadenectomy }\end{array}$ & T1bN3aM1 ${ }^{\circ \circ}$ \\
\hline Case 13 & antrum & T3N1M0 & NP & $\mathrm{T} 2 \mathrm{~N} 1^{\circ} \mathrm{MO}$ & 3FLOT & $\begin{array}{l}\text { Subtotal gastrectomy+D2 } \\
\text { lymphadenectomy }\end{array}$ & T2N1MO \\
\hline Case 14 & antrum & T4aN2MO & NP & T4aN2M1 $1 * \star \star$ & 4FLOT & Laparoscopic Gastroenteroanastomosis & $\begin{array}{l}\text { Liver } \\
\text { metastases }\end{array}$ \\
\hline Case 15 & antrum & T4aN2M0 & NP & T4aN2MO & 3 FLOT & $\begin{array}{l}\text { Subtotal gastrectomy+D1 } \beta \\
\text { lymphadenectomy }\end{array}$ & T3N3MOL1 \\
\hline Case 16 & corpus & T2N1M0 & NP & T4aN2MO & 3 FLOT & Gastrectomy+D1 $\beta$ lymphadenectomy & T4aN2MO \\
\hline Case 17 & antrum & T3N1M0 & T3N1M0 & $\mathrm{T}_{4} \mathrm{aN} 2^{\circ} \mathrm{MO}$ & $3 F O X$ & Subtotal gastrectomy + D2 lymphadenectomy & T3N2M0 \\
\hline Case 18 & $\begin{array}{l}\text { corpus }+ \text { antrum } \\
\text { synchronous tumors) }\end{array}$ & S) & T1N0 & T2NOMO & No & Gastrectomy +D2 lymphadenectomy & T1bN1M0L1 \\
\hline Case 19 & corpus & T3N1 & No & T2NO & No & $\begin{array}{l}\text { Laparoscopic subtotal gastrectomy+ } \\
\text { D2 lymphadenectomy }\end{array}$ & T2NOMO \\
\hline Case 20 & gastric angulus & TXNOMO & T1aNOMO & T1NOMO & NO & Laparoscopicwedge resection $* * * *$ & T1NOMO \\
\hline \multicolumn{8}{|c|}{$\begin{array}{l}\text { *Biopsy of the tumor with Tru-cut needle during staging laparoscopy to settlethe diagnostic after consecutive negative endoscopic biopsy } \\
{ }^{\circ} \text { Excision biopsy of suspected lymph node on staging laparoscopy }\end{array}$} \\
\hline \multicolumn{8}{|c|}{$\begin{array}{l}¥ \text { - Excised lymph node during staging laparoscopy was positive for adenocarcinoma } \\
\star \star \text {-tumor suspected to invade aortic wall }\end{array}$} \\
\hline \multicolumn{7}{|c|}{ ? suspicion of peritumoral localized carcinomatosis - biopsy } & $\begin{array}{l}\text { ? suspicion of peritumoral localized carcinomatosis - biopsy } \\
{ }^{\circ} \text { Laparoscopic staging was performed only after neoadjuvant chemotherapy }\end{array}$ \\
\hline \multicolumn{8}{|c|}{ ?? $5 \mathrm{~mm}$ tumor on the hepatic capsule of the segment 3rd suspected for metastasis - frozen biopsy: calcification, no tumor cells } \\
\hline \multicolumn{8}{|c|}{ \# hepatic nodule - peritoneal carcinomatosis } \\
\hline \multicolumn{8}{|c|}{ 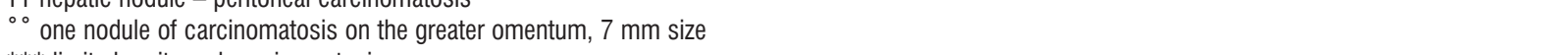 } \\
\hline$\star * \star * \operatorname{sev}$ & re cardiovascular cor & omorbidities: & le aor & 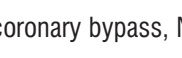 & & & \\
\hline
\end{tabular}

regional tumor (cT3,4 or $\mathrm{cN}+)$ with high risk (T1,2 N0) more than $2 \mathrm{~cm}$ in size (cases 18-20) for occult peritoneal seeding (cases 9-17), iii) and vi) gastric tumors highly suggestive for suspicion of invasion into the wall of the aorta malignancy on endoscopy and CT scan but (case 6), iv) discrepancy between CT and EUS with two consecutive benign endoscopic biopsy staging (cases 4 and 5), v) early gastric cancer (cases 1-3). 
Laparoscopic ultrasound was performed in all patients except one, when ultrasound was not available. Laparoscopic staging associated with percutaneous transparietal Tru-cut biopsy from the tumor set the diagnosis of adenocarcinoma in 2 cases of consecutive endoscopic biopsies of high grade dysplasia. In another patient with chronic pancreatitis and chronic gastritis, with a thickened area in the posterior gastric wall highly suspicious of gastric cancer on endoscopy and CT scan, the LUS-guided Trucut biopsy proved to be a benign inflammatory modification. This patient was treated with PPI and the follow-up upper GI endoscopies performed in the next 4 years showed regression of the modified area.

In eight patients, laparoscopic staging was associated with biopsy of the loco-regional suspected lymph nodes. This approach allowed better staging and set the indication for neoadjuvant chemotherapy in 4 of the eight cases (50\%).

Eight patients with locally advanced tumors had peritoneal washing with cytology during laparoscopic staging. In all cases the cytology was negative.

Extensive peritoneal carcinomatosis, defined as involvement of more than one peritoneal region, was detected by staging laparoscopy in three cases ( $15 \%$ of all patients) and set the indication for palliative chemotherapy.

Staging laparoscopy has settled the dilemma in one patient with large discrepancy between $\mathrm{CT}$ and EUS. EUS revealed a T1N0 tumor while CT showed a $15 \mathrm{~mm}$ diameter T3N1 tumor situated into the fornix. On laparoscopy and LUS the tumor was diagnosed as T3N1 and the biopsied lymph node was positive, setting thus the indication for perioperative chemotherapy. On the subsequent radical total gastrectomy, the tumor showed complete response to chemotherapy.

In one patient with high anesthetic risk for major radical surgery due to history of myocardial infarction and severe cardiovascular $\mathrm{co}^{-}$ morbidities diagnosed with T1N0 gastric cancer, laparoscopic staging with LUS confirmed the T1N0 stage and consequently, a laparoscopic wedge resection of the stomach with clear margin was performed in the same anesthetic event, the patient experiencing a quick and favorable postoperative outcome and no recurrence after 30 months follow-up.

The median operative time for the laparoscopic staging procedure was 40 minutes (range: 25-60 min) including the time required to perform LUS and biopsies. The intraoperative blood loss was negligible. The postoperative outcome after staging laparoscopy was quickly favorable; patients were able to ambulate in the evening of the operative day and were discharged the next day if neoadjuvant chemotherapy was indicated. For those that went to upfront surgery, that was performed within the next three days from staging laparoscopy.

Patients with lymph nodes biopsies and neoadjuvant therapy had an inflammatory scar visible at the area of biopsy at the time of radical surgery but that did not influence the ability to perform a sound D2 lymphadenectomy. In one patient with loco-regional carcinomatosis at the time of staging laparoscopy which developed liver metastases during the course of neoadjuvant chemotherapy and did not undergo further surgery, metastases on the sites of port insertions developed at 1 year after staging laparoscopy, together with advanced carcinomatosis and progression of systemic disease.

\section{Discussion}

Accurate staging in gastric cancer allows optimal individualization of the treatment protocol and provides patients with the best option both for cure or palliation. First reported in 1984, the procedure of staging laparoscopy for gastric cancer was since evaluated in several reports (10-14). Nowadays, laparoscopic staging has become recognized as a standard procedure, being recommended by the 2018 Edition of the NCCN Clinical Practice Guidelines in Oncology in patients with gastric cancer either to guide selection of cases that need perioperative chemotherapy or to prevent a non-therapeutic laparotomy when metastatic disease is not detected on CT scan (15). The European Society of Medical 
Oncology (ESMO), Society of American Gastrointestinal and Endoscopic Surgeons (SAGES) and many other oncological surgical societies also emphasize the value of staging laparoscopy in the management of gastric cancer but it is still not routinely adopted in the clinical practice $(3,16-18)$. One possible explanation for this reluctance of surgical teams is that staging laparoscopy is perceived as an adjunct procedure that consumes a part of the time reserved for the forthcoming tedious radical operation. Another explanation may be the lack of adherence to the strict indications of the perioperative chemotherapy protocol and the decision of surgical teams to choose upfront surgery in resectable T3N0-1 cases. In light of these considerations we intended to present a review of indications for staging laparoscopy and provide a real-life scenario example on the value of this investigation in a series of patients operated by our surgical team.

The first question the surgeon needs to answer is if one particular patient has an indication for staging laparoscopy. Its major indications are advanced T3-4 tumors which breach the serosa and may have a $25 \%$ high risk for peritoneal metastases especially in poorly differentiated, N+ tumors (1). Another indication is to assess resectability in locally advanced tumors suspected on CT scan to invade adjacent structures and to identify any localized peritoneal tumoral deposits that might disappear under neoadjuvant chemotherapy by the time of radical surgery. A new indication has emerged recently with the widespread use of neoadjuvant chemotherapy for gastric cancer. This represents a large number of patients which are staged routinely with $\mathrm{CE}-\mathrm{CT}$ and EUS. As CE-CT and EUS actually have a suboptimal accuracy for differentiation of T2 from T3 tumors and for detection of lymph nodes metastases and there is sometimes a mismatch between them, laparoscopy can settle the dilemma for good and send the patient on the correct treatment plan: either upfront surgery or neoadjuvant chemotherapy followed by surgery.

In our routine practice, patients with $\mathrm{T} 1$ tumors are spared a staging laparoscopy because the risk of lymph node metastases is low. Otherwise, patients with T2 tumors are staged to exclude a more advanced T3 lesion or presence of lymph node metastases - LUS being helpful in this regard and lymph node biopsies or sampling being done for definitive pathological assessment. Patients with ascites and obvious nodules of carcinomatosis are also spared a laparoscopy as in these cases there is no discussion about a surgical treatment with curative intend.

Staging laparoscopy was performed as an individual procedure and not as an introductory phase of the radical operation in order to remove the pressure of time away from the surgical team and to perform a throughout exploration of all peritoneal quadrants, a careful examination of the tumor and the lymphatic basin and biopsies if necessary. If upfront surgery was decided, it was performed within the next days after the results of staging were discussed within the oncological board and with the patient.

In our series, the association of staging laparoscopy to the conventional investigations provided additional information in 13 patients representing $65 \%$ of the total 20 cases, comparable with data from the literature, and actually changed the treatment protocol in 30\% of patients, a figure that is slightly higher than previous reports maybe due to the rigorousness of selection of patients for perioperative chemotherapy (19). Of these, in 3 cases $(15 \%$ of the total 20 patients) the addition of laparos ${ }^{-}$ copic staging to CE-CT scan and EUS has changed the decision of management from upfront surgery to perioperative chemotherapy while in three further cases (15\%) laparoscopy identified carcinomatosis that was not clearly described on the CE-CT scan and redirected patients towards palliative definite chemotherapy. In $50 \%$ of the cases in which lymph node biopsy was performed it was positive for metastasis and directed the patient towards perioperative chemotherapy. In another three cases (15\%) laparoscopy coupled with Tru-Cut biopsies has settled the definitive diagnosis that was unclear after repeated endoscopic biopsies.

None of our patients suffered any incidents 
or side-effects during or after laparoscopic staging, they were ready for radical surgery within the next days if necessary and were discharged the day after the procedure if neoadjuvant chemotherapy was decided. The scars produced by staging laparoscopy, although present especially if one or more lymph nodes were excised for biopsy, did not interfere significantly with the operative technique at the time of definitive surgery. Moreover, the visual representation of the tumor before chemotherapy and exact identification of the tumor location allowed the surgeon to prepare better for the radical surgery and also enabled a better assessment of the efficacy of chemotherapy.

\section{Conclusion}

In conclusion, laparoscopy is the ultimate staging tool in the hands of the surgeons and should not be ignored during the preoperative workup of patients with gastric cancer. It provides valuable information leading to a change in the treatment pathway in up to $30 \%$ of the cases. In order to take advantage of its entire potential, laparoscopic staging should ideally be performed as an independent procedure and in combination with other tools such as lymph node biopsies and laparoscopic ultrasound.

\section{Conflicts of interest}

There is no conflict of interests.

\section{Authors' Contributions}

Vasile Bintintan - study design, collection of data, data analysis, draft of the manuscript, review of the manuscript, final proof. Andreea Cordos - collection of data, data analysis, review of the literature, draft of the manuscript, review of the manuscript. Romeo Chira - study design, review of the literature, review of the manuscript. Simona Cocu - collection of data, review of the literature. Paul Rus - collection of data, review of the literature. Adriana Bintintan collection of data, review of the literature, review of the manuscript. Georgiana Nagy - collection of data, review of the literature, review of the manuscript. Larisa Ciule collection of data, review of the literature, review of the manuscript. Emanuel Cata collection of data, data analysis. Andrei Pop collection of data, data analysis. Vlad Fagarasan - collection of data, data analysis. Andrei Ungureanu - collection of data, review of the literature. Valeriu Surlin - review of the literature, review of the manuscript. Dan Timofte - review of the literature, review of the manuscript. Kim Young Woo - review of the manuscript. Constantin Ciuce - review of the manuscript. George Dindelegan - review of the manuscript. All authors contributed to the final manuscript.

\section{Acknowledgements}

i) This study was partly supported by the UEFISCDI project PN-III-P2-2.1-PED2016-0783 Project No. 238 from 17/08/2017, Core Project No. PN 1803 01/02

ii) Many thanks to Prof Dr. Johannes Zacherl, University of Vienna, Allgemeines Krankenhaus Wien, which firstly introduced us to the concept of laparoscopic staging in gastric cancer in 2008.

\section{References}

1. Power D, Schattner M, Gerdes H, et al. Endoscopic ultrasound can improve the selection for laparoscopy in patients with localized gastric cancer.J Am Coll Surg. 2009 Feb;208(2):173-8.

2. Cunningham D, Allum WH, Stenning SP et al. Perioperative chemotherapy versus surgery alone for resectable gastroesophageal cancer. N Engl J Med 2006; 355: 11-20

3. Cardoso R, Coburn N, Seevaratnam R, et al. A systematic review and meta-analysis of the utility of EUS for preoperative staging for gastric cancer. Gastric Cancer 2012;15(Suppl 1):S19-S26.

4. Hayes T, Smyth E, Riddell A, et al. Staging in Esophageal and Gastric Cancers.Hematol Oncol Clin North Am 2017; 31(3), 427-440.

5. Korenblit J, Anantharaman A, Loren D, et al. The role of endoscopic ultrasound-guided fine needle aspiration (eus-fna) for the diagnosis of intra-abdominal lymphadenopathy of unknown origin. J Interv Gastroenterol. 2012;2(4):172-176.

6. Wang J, Chen Q, Wu X, et al. Role of endoscopic ultrasound-guided fine-needle aspiration in evaluating mediastinal and intraabdominal lymphadenopathies of unknown origin. Oncol Lett. 2018;15(5):6991-6999

7. Seevaratnam R, Cardoso R, McGregor C, et al.How useful is preoperative imaging for tumor, node, metastasis (TNM) stagingof gastric cancer? A meta-analysis. Gastric Cancer 2012;15(Suppl1): S3-S18.

8. Nie R, Yuan S, Chen X, et al. Endoscopic ultrasonography com- 
pared with multidetector computed tomography for the preoperative staging of gastric cancer: a meta-analysis.World J Surg Oncol. 2017 Jun 2;15(1):113

9. Gross E, Bancewicz J, Ingram G. Assessment of gastric cancer by laparoscopy. Br Med J (Clin Res Ed). 1984;288(6430):1577.

10. Munteanu V, Oniu T, Bintintan V, et al. Staging laparoscopy in digestive cancers. J Gastrointestin Liver Dis. 2009 Dec;18(4):461-7

11. Hu Y, Deng Z, Liu H, et al. Staging laparoscopy improves treatment decision-making for advanced gastric cancer.World $J$ Gastroenterol. 2016 Feb 7;22(5):1859-68.

12. Santa-Maria A, Valadăo $M$, Iglesias A.The role of staging laparoscopy in treatment of locally advanced gastric cancer. Surg Laparosc Endosc Percutan Tech. 2014 Oct;24(5):434-9.

13. Ishigami S, Uenosono $\mathrm{Y}$, Arigami T, et al. Clinical utility of perioperative staging laparoscopy for advanced gastric cancer.World $\mathrm{J}$ Surg Oncol. 2014 Nov 18;12:350

14. NCCN Clinical Practice Guidelines in Oncology. Gastric Cancer
Version 2.2018. Available at: https://www.nccn.org/professionals/physician_gls/pdf/gastric.pdf

15. Smyth EC, Verheij M, Allum W, et al. Gastric cancer: ESMOClinical Practice Guidelines for diagnosis, treatment and follow-up.Ann Oncol 2016;27:v38-v49.

16. https://www.sages.org/publications/guidelines/guidelines-fordiagnostic-laparoscopy/, Board of Governors of the Society ofAmerican Gastrointestinal and Endoscopic Surgeons (SAGES), 2010.

17. Moehler M, Al-Batran SE, Andus T, et al. German S3-guideline "Diagnosis and treatment of esophagogastric cancer". Z Gastrenterol 2011;49:461-531.

18. Japanese Gastric Cancer Association. Japanese gastric cancer treatment guidelines 2010 (ver. 3). Gastric Cancer 2011;14:113-123.

19. Leake P, Cardoso R, Seevaratnam R, et al. A systematic review of the accuracy and indications for diagnostic laparoscopy prior to curative-intent resection of gastric cancer.Gastric Cancer. 2012 Sep;15 Suppl 1:S38-47. 